\title{
MEMÓRIA, GÊNERO E ANTIRRACISMO: \\ a trajetória de lutas da atriz Ruth de Souza
}

Memory, gender and anti-racism: The trajectory of fights of the Actress Ruth de Souza

Memoria, género y Antirracismo: La trayectoria de luchas de la actriz Ruth de Souza

PALAVRAS-CHAVE: Memória; História do Gênero; Antirrascismo.

KEYWORDS: Memory; Gender; Anti-racism.

PALABRAS CLAVE: Memoria; Género; Antirracismo.

SILVA, Julio Claudio da. Uma Estrela Negra no teatro brasileiro. Relações raciais e de gênero nas memórias de Ruth de Souza (1945-1952). Manaus: UEA Edições, 2017.

Vitor Leandro de Souza*

O livro de Julio Claudio da Silva, Uma Estrela Negra no Teatro Brasileiro, é fruto da esmerada pesquisa para a tese de doutorado apresentada ao Programa de Pós-Graduação em História da Universidade Federal Fluminense (UFF). Se insere nas discussões sobre o papel dos negros, e negras, na sociedade brasileira do pós-Abolição e as tensas relações raciais tão presentes no pensamento intelectual brasileiro das primeiras décadas do século XX.

Tomando como referencial a bem-sucedida carreira da atriz negra Ruth de Souza, o historiador problematiza as relações raciais, de gênero, a construção e reconstrução da memória da atriz, e as tensas dimensões vivenciadas por ela, pelo direito de inserir-se no complexo universo cultural brasileiro.

Esse exercício apurado de análise da memória pública de Ruth de Souza, de sua problemática, e da sua relação com as questões raciais e de gênero é o principal caminho trilhado por ele para dar destaque às lutas sociais e culturais de artistas negros entre as décadas de 1930 e 1950, e as profundas conexões dessas lutas com a vida política brasileira do período.

Professor da Universidade do Estado do Amazonas, Julio Claudio da Silva realizou sua formação como historiador na UFF. E ao longo de sua trajetória como pesquisador, tem se

\footnotetext{
*Mestre em História Social pela Universidade Federal do Rio de Janeiro. Atualmente é Doutorando em História Social da Cultura pela Pontifícia Universidade Católica do Rio de Janeiro. Contato: R. Marquês de São Vicente, 225, Gávea, CEP: 22451-900, Rio de Janeiro, RJ, Brasil. E-mail: vitorleandro@id.uff.br. ORCID: https://orcid.org/0000-0002-9869-8907.
} 
dedicado a investigar a questão racial no Brasil, e os desdobramentos correlatos a temática, como a História África e da Cultura Afrobrasileira, o Movimento Negro, e a memória e trajetória dos/as intelectuais negros/as.

Assim, algumas das inquietações do pesquisador podem ser percebidas no livro Uma Estrela Negra no Teatro Brasileiro, que em seu argumento central tem como proposta refletir sobre as relações raciais e de gênero no Brasil a partir da recuperação de alguns aspectos da memória e trajetória da atriz brasileira Ruth de Souza. Passando ainda pela história de umas das importantes associações negras do século XX, o Teatro Experimental do Negro.

Um dos esforços da narrativa do autor ao longo dos capítulos consiste em historicizar e refletir a temática do racismo no Brasil, visando contribuir com novas formulações e respostas para os estudos das relações raciais e de gênero (p. 21-23). ${ }^{1}$ Desse modo, O trabalho insere-se no diálogo com a ampla produção historiográfica que analisa os processos de construção de conceitos como raça, relações raciais e da identidade negra na sociedade brasileira. ${ }^{2}$ Especialmente na discussão que considera a identidade não somente como uma ideia, desligada da realidade concreta, mas que, antes de tudo, se manifesta na realidade social. $^{3}$

Preocupado com as formas complexas dos processos ligados à cidadania nas sociedades pós-emancipação, as questões levantadas pelo autor ao longo de sua pesquisa buscaram evidenciar, a partir da trajetória artística da jovem Ruth de Souza, como a racismo se manifestou de forma muito particular para as mulheres negras. ${ }^{4}$ Debruçando-se sobre a história da atriz, Silva procura observar "os processos de construção de memórias e os limites estabelecidos pelas relações raciais e de gênero, em uma sociedade pretensamente meritocrata fundada sobre o mito da democracia racial" (p. 25). Para tal, a figura de Ruth de Souza favorece a problematização das temáticas raciais e a generificação nos palcos brasileiros, uma vez que como mulher, afrodescendente, e proveniente das classes subalternas, ela conquistou reconhecimento, conseguindo se profissionalizar como uma das primeiras atrizes com esse perfil a fazer teatro erudito no nosso país.

O autor segue a tradição de estudos ligados à história social, fazendo uso da biografia de Ruth de Souza para compreender as dinâmicas da modernização do teatro brasileiro e como a questão racial e de gênero impactaram nesse processo. Como estratégia, Julio Claudio da Silva utiliza-se de depoimentos concedidos pela atriz em diversas décadas, assim como de relatos fornecidos por seus contemporâneos, e ainda da reunião de reportagens publicadas nos anos 1940 e 1950 selecionadas pela própria Ruth de Souza ao construir seu acervo pessoal. 
Na primeira parte do seu livro, composta por dois capítulos, a analise do autor recai sobre os anos iniciais da carreira de Ruth de Souza como atriz no Teatro Experimental do Negro. Silva utiliza-se dos pressupostos metodológicos da História Oral, para problematizar a memória narrada dos entrevistados, demonstrando que a memória faz muito mais referencia ao presente que ao passado.

As tensões diante da recuperação da memória, os silêncios e esquecimentos foram analisadas pelo autor sem perder de vistas a dimensão política, que se mostrava marcadamente nas vivências de Ruth de Souza desde sua infância pobre, ao lado de sua mãe, viúva e empregada doméstica. Mas que, apaixonada pelas artes cênicas, ousou ser atriz.

Ao introduzir o leitor, logo no primeiro capítulo, na discussão dos conceitos memória, gênero e cultura afro-brasileira - os três pilares teóricos fundamentais para o desenvolvimento de sua argumentação nos capítulos seguintes, o autor pretende fundamentar os conceitos de sua pesquisa tendo como ponto de partida os depoimentos cedidos a ele pela própria Ruth de Souza. E com sensibilidade apurada e comprometida, Julio de Souza, além de dar visibilidade para os primeiros anos da trajetória da atriz, insere aos leitores e leitoras na bela história de homens e mulheres do Rio de Janeiro efervescente das décadas de 1930 e 1940.

A luta de Ruth de Souza, e de seus contemporâneos do Teatro Experimental do Negro, por maiores oportunidades na dramaturgia brasileira demonstram o quanto são racializadas as relações sociais no Brasil. Investigando os laços de amizade e as redes de solidariedade utilizadas pela atriz para conquistar seu espaço no cenário artístico brasileiro o autor nos conduz por um amplo universo de personagens engajados no combate às desigualdades e de lutas em meio à intensa exclusão do Rio de Janeiro de inícios do século $\mathrm{XX}$.

Apesar dos entraves impostos pelo racismo cordial brasileiro, e pela suposta democracia racial, o autor realiza um cruzamento entre os depoimentos da atriz e recortes de jornais que apresentam muitas informações sobre o início da sua carreira, destacando a dimensão política de lutas e embates, por vezes "esquecida" nos relatos de Ruth de Souza, mas recuperada nos textos dos seus contemporâneos. Um exemplo disso é o depoimento de Raquel da Trindade sobre os primeiros anos de atuação do Teatro Experimental do Negro e das estratégias utilizadas por aqueles sujeitos na luta contra o racismo, especialmente as formas de racismo tão comuns nos palcos brasileiros daqueles anos.

As preocupações com novas questões que pudessem complexificar as narrativas elaboradas pela atriz Ruth de Souza nas entrevistas dadas ao autor, e a promoção do diálogo 
entre esses depoimentos com outras falas da atriz em gravações que estão sob guarda do Museu da Imagem e do Som do Rio de Janeiro (MIS RJ), constituem o segundo capítulo do livro. Nele, Julio Claudio da Silva dá particular atenção para as tensões, lacunas e contradições desses relatos, e como novas questões propostas por ele podem ampliar o campo de análise, permitindo compreendermos as estratégias utilizadas pela atriz na elaboração, e reelaboração, da memória sobre a ausência de oportunidades para uma jovem negra e pobre no campo teatral das décadas de 1930 e 1940.

A redação envolvente de Julio Claudio de Silva, e sua apurada análise apontam para ambiguidades nos depoimentos de Ruth de Souza, especialmente quanto a racialização do teatro, e como em alguns momentos a atriz atribui seu sucesso quase que unicamente a seu mérito, "desracializando" obstáculos de sua trajetória, e sublimando sua condição de artista afrodescendente, que viveu intensamente a realidade de exclusão imposta pelas artes cênicas no Brasil.

$\mathrm{Na}$ segunda parte do livro, o autor dedica-se a investigar o complexo processo de “arquivamento de si” e do Teatro Experimental Negro realizado pela própria Ruth de Souza. Para tal, Julio Claudio da Silva faz uso dos registros sobre a vida da atriz e da companhia de teatro reunidos no "Acervo Ruth de Souza”, do Laboratório de História Oral, da Universidade Federal Fluminense (LABHOI UFF). A intenção de Silva consiste em compreender os níveis de retroalimentação que os recortes de jornais reunidos pela própria Ruth de Souza tiveram sobre sua memória e, até certo modo, ancoraram o relato que a atriz fez de si.

Ao atentar para os silêncios presentes nos relatos da "Dama Negra do Teatro", o autor recupera a organização de uma rede de alianças formadas em torno do grupo de artistas ligados ao Teatro Experimental do Negro, bem como a importância do grupo para o processo de modernização do teatro brasileiro, e das iniciativas de combate ao racismo no Rio de Janeiro do período. No capítulo 3, ao cotejar a documentação do Acervo Ruth de Souza, o historiador mergulha na problemática relativa às restrições impostas aos artistas afrodescendentes nos palcos, e como tais práticas, seja nos locais, ou mesmo na forma com que eram mostrados nos espetáculos teatrais, se materializavam frequentemente.

Desse modo, ao recuperar a memória sobre o papel da companhia Teatro Experimental do Negro, a narrativa de Silva nos apresenta "acirradas batalhas de memória entre Paschoal Carlos Magno e Abdias Nascimento" em torno da "paternidade da entidade" (p. 128), e como tais embates foram capazes de complexificar ainda mais a história de uma das mais importantes manifestações culturais do movimento negro brasileiro. Assim, o capítulo nos fornece amplamente uma riqueza considerável de informações sobre o panorama 
teatral brasileiro do período, especialmente quanto às dificuldades de funcionamento, e estratégias usadas pelos artistas do Teatro Experimental do Negro nas lutas contra "o complexo de inferioridade do negro e contra o preconceito de cor dos brancos", como parafraseia o próprio autor (p. 134).

É especialmente bem sucedida a escolha de Silva ao investigar o grupo de artistas ligados ao Teatro Experimental do Negro, pois permite aos leitores a compreensão da importância da entidade para os artistas e para a cultura brasileira, justamente por criar e organizar uma "nova modalidade do teatro negro no Brasil" (p. 141). Mostrando o compromisso daqueles sujeitos em constituir espaços igualitários, que permitissem atuar plenamente como artistas, verem representados com justiça o seu universo étnico-racial e, portanto, contribuindo para a elevação cultural e dos valores individuais dos negros (p. 163).

No capítulo quatro, Julio Claudio da Silva busca investigar os limites e possibilidades para a construção de um teatro negro no Brasil da década de 1940 (p. 167). Para isso, o autor utiliza a cobertura dada pela imprensa sobre os espetáculos montados pelo Teatro Experimental do Negro, a partir dos recortes guardados pela atriz Ruth de Souza, tentando compreender como os críticos teatrais viam as adaptações de peças teatrais estrangeiros para o público brasileiro pelos artistas da entidade, e também as percepções racializadas sobre a atuação dos atores e atrizes da companhia de teatro.

Deslocando o foco de análise para os possíveis diálogos entre o palco e a platéia o autor analisa as montagens dos espetáculos estrangeiros $O$ Imperador Jones, Todos os filhos de Deus têm asas e O Moleque sonhador, de autoria de Eugene O’Neill. Assim como os espetáculos escritos por brasileiros especialmente para o Teatro Experimental de Negros, como a peça $O$ filho pródigo, de Lucio Cardoso, ou a Aruanda, escrita por Joaquim Ribeiro; e por fim a peça Filho de Santo, escrita por José Moraes Pinho. Dessa maneira, Silva nos auxilia a compreender como a montagem de espetáculos com temas ligados à realidade afrodescendente se constituiu elemento primordial para o crescimento das artes, e particularmente do teatro, no Brasil.

Montados entre os anos de 1945 e 1949, os textos iluminam "temáticas sócioculturais das populações e culturas afrodescendentes" (p. 168), e tal esforço de destaque da cultura negra é reconhecido pelos críticos como iniciativa fundamental no complexo cenário de lutas contra o racismo tão presente na sociedade brasileira. O olhar multifacetado do autor revelou um esforço de pesquisa que nos indica o quanto racialização cultural não passava somente pelos palcos, mas também pelo espaço destinado aos espectadores, e de como o grupo de artistas reunidos em torno do Teatro Experimental do Negro consolidava-se 
paulatinamente como uma espécie de oásis artístico em que era possível difundir textos e performances antirracistas, em que os artistas negros pudessem também apresentar sua arte e seu talento.

Por fim, no último capítulo, Silva dedica-se aos anos em que a atriz Ruth de Souza desliga-se do Teatro Experimental do Negro e vai para o exterior, onde tem a oportunidade de estudar artes cênicas nos Estados Unidos da América. O episódio, descrito pelo historiador como "um divisor de águas" na vida profissional da artista, revela o quão fundamental foi o apoio recebido pela atriz e o quanto a rede de solidariedades em que ela estava inserida foi primordial para o seu processo aprimoramento e profissionalização.

Essa temporada de estudos no exterior, de fato, abriu novas portas para a atriz, proporcionando a ela novos contratos, e uma carreira em ascensão nas principais companhias de cinema dos anos 1940 e 1950. Mesmo diante da tensão e do preconceito expressos na oferta de pequenos papeis para a atriz negra, seu talento e esforço foram reconhecidos em prêmios e indicações importantes pro seguimento, seja no Brasil ou ainda internacionalmente.

Ao se deparar com as questões metodológicas em torno da memória e do racismo na sociedade brasileira, o autor enfrenta o desafio de nos apresentar um texto rico teoricamente e que contribui amplamente com as discussões sobre os papéis da mulher negra no Brasil, especialmente no cenário cultural e político do pós Abolição, por meio da trajetória de uma mulher negra, que ousou ser artista, em uma sociedade que negou, e continua negligenciando, os direitos básicos aos afrodescendentes.

\section{Notas}

\footnotetext{
${ }^{1}$ Optei em citar ao longo da resenha, entre aspas, palavras do próprio Julio Claudio da Silva, ou citações feitas por ele no livro.

${ }^{2}$ Ver os trabalhos de GUIMARÃES, Antonio Sergio Alfredo. Classes, Raça e Democracia. São Paulo: Fapesp; Editora 34, 2002; SCHWARCZ, Lilia Moritz. O espetáculo das raças: cientistas, instituições e questão racial no Brasil, 1870-1930. São Paulo: Companhia das Letras, 1993; SKIDMORE, Thomas E. Preto no branco: raça e nacionalidade no pensamento brasileiro. Rio de Janeiro: Paz e Terra, 1976.

${ }^{3}$ NASCIMENTO, Elisa Larkin. O sortilégio da cor: identidade, raça e gênero no Brasil. São Paulo: Selo Negro, 2003.

${ }^{4}$ O debate tem sido feito em trabalhos como o de ALMADA, Sandra. Damas Negras: sucesso, lutas e discriminação: Xica Xavier, Lea Garcia, Ruth de Souza, Zezé Motta. Rio de Janeiro: Mauad, 1995; ARAÚJO, Joel Zito Almeida de. A negação do Brasil: o negro na telenovela brasileira. São Paulo: Editora Senac, 2000.
} 